\title{
Complutum
}

ISSN: 1131-6993

\section{El abrigo con pintura esquemática de Pala de Cabras (Ourense). Encuentros y desencuentros entre dos tradiciones}

\author{
Manuel Santos-Estevez ${ }^{1}$; Carlos Tejerizo-García²; Francisco Alonso Toucido
}

Recibido: 05 de junio de 2020 / Aceptado: 17 de julio de 2020

Resumen. Los resultados del presente estudio han permitido redefinir la iconografía del abrigo de Pala de Cabras (Ourense). Este yacimiento, con 15 paneles, constituye uno de los conjuntos con Arte Esquemático más complejos del noroeste de la Península Ibérica. Entre las figuras pintadas destacan 3 representaciones de las llamadas figuras oculadas, soliformes, ramiformes y zig-zags. La identificación de nuevas figuras obliga a una revisión del marco cronológico del yacimiento y, por lo tanto, a un nuevo análisis de su contexto cultural dentro de las regiones rupestres de la Península Ibérica. La presencia de este abrigo en las sierras orientales gallegas, está ayudando a definir la zona de encuentro entre dos tradiciones rupestres: la Esquemática y la Atlántica.

Palabras clave: Arte Esquemático; Arte Atlántico; figuras oculadas; noroeste ibérico; Prehistoria Reciente

[en] The rock art shelter of Pala de Cabras (Ourense). Encounters and disagreements between two traditions

Abstract. The results of this study allow for a review of the iconography in Pala de Cabras rock-shelter (Ourense). This site, with 15 art panels, is one of the most complex sites with Iberian Schematic Art in the Northwestern part of Iberia. Within this ensemble, three representations of the so-called eyed-idols, soliforms, ramiforms and zig-zags stand out. The identification of new figures implied the revision of the chronological frame of this rock art site and, therefore, implies a new analisys on its cultural context into the Iberian rock art regions. The presence of this rock-shelter in the eastern Galician mountain range is helping to define the encounter zone of two different rock art traditions: the Schematic art and the Atlantic art.

Keywords: Iberian Schematic Art; Atlantic Art; eyed-idols; northwestern Iberia; Late Prehistory

Sumario. Circunstancias del hallazgo. Localización y contexto arqueológico. Descripción del abrigo y de las pinturas. Estado de conservación de las pinturas. Valoración general de las pinturas y su cronología. Pala de Cabras en el contexto del Arte Esquemático del noroeste ibérico. Agradecimientos. Bibliografía.

Cómo citar: Santos-Estevez, M.; Tejerizo-García, C.; Alonso Toucido, F. (2020). El abrigo con pintura esquemática de Pala de Cabras (Ourense). Encuentros y desencuentros entre dos tradiciones. Complutum, 31 (1): 7-24.

\section{Circunstancias del hallazgo}

Las pinturas de Pala de Cabras, fueron descubiertas durante el desarrollo del proyecto arqueológico Sputnik Labrego ${ }^{4}$, en el trans- curso de los trabajos de prospección orientados al estudio de la presencia de la guerrilla antifranquista en lo que en su día fue conocida como la Ciudad de la Selva en la parroquia de Casaio, término municipal de

FCT, Lab2.pt, Universidade do Minho

manuel.santos@mundo-r.com

2 Universidad del País Vasco

carlosteje@gmail.com

3 USC, Tempos Arqueólogos SL

franalonsotoucido@hotmail.com

4 Sputnik Labrego. Resilencia e resistencia labrega galega en “momentos de perigo”; unha análise antropolóxica e arqueolóxica na longa duración. Dirigido por Carlos Tejerizo, financiado por la Xunta de Galicia y realizado en el marco del Proyecto “Agencia campesina y complejidad sociopolítica en el noroeste de la Península Ibérica en época medieval" (Ministerio de Economía, Industria y Competitividad, AEI/FEDER UE HUM2016-76094-C4-2-R), del Grupo de Investigación en Arqueología Medieval, Patrimonialización y Paisajes Culturales / Erdi Aroko Arkeologia, Ondaregintza eta Kultur Paisaiak Ikerketa Taldea (Gobierno Vasco, IT1193-19) y del Grupo de Estudios Rurales (Unidad Asociada UPV/EHU-CSIC). 
Carballeda de Valdeorras situado en la parte más oriental de la provincia de Ourense. Pala de Cabras fue localizado gracias a la información facilitada por dos vecinos de $\mathrm{Ca}$ saio: Francisco Fernández y César Real. La razón que motivó la visita al abrigo, el 5 de febrero de 2019, fue la presencia de una choza relacionada con la guerrilla asentada en la zona durante la Guerra Civil y la postguerra (Tejerizo y Gutiérrez, 2019). Efectivamente, dicha construcción fue localizada en el interior del abrigo. Aunque el objetivo de la visita no era, en principio, la localización de otro tipo de elementos arqueológicos, observando las características naturales del lugar y sus semejanzas con otros sitios con pinturas esquemáticas, se tomó la decisión de inspeccionar detenidamente las distintas superficies de la covacha, momento en el que fueron descubiertas las pinturas rupestres. De este modo, fueron identificadas pinturas en tonalidades rojizas en la mayor parte de las superficies verticales de la pared norte de Pala de Cabras, entre ellas, llamó la atención la presencia de las denominadas figuras oculadas, diseño muy infrecuente en el cuadrante noroeste de la Península Ibérica.

El hallazgo de Pala de Cabras, motivó la publicación de un artículo con una primera valoración de las pinturas (Tejerizo-García et al. 2020). Durante un detenido estudio realizado con posterioridad a esta última publicación, fueron identificas nuevas figuras que permiten una revalorización de la iconografía del abrigo, así como una revisión del marco cronológico del yacimiento rupestre.

\section{Localización y contexto arqueológico}

El abrigo de Pala de Cabras se localiza cerca de la ermita de San Xil en la parroquia de Sta. María de Casaio. Sus coordenadas UTM (huso $29)$ son: $\mathrm{X}: 680.857,13$; Y: 4.686.028,40. Altitud: 860 m.s.n.m. ${ }^{5}$

Esta pala, como así son denominados este tipo de abrigos en gallego y portugués, se encuentra en la vertiente norte del valle por el

Las primeras observaciones sobre las pinturas de Pala de Cabras han sido presentadas a través de la comunicación titulada: Mirando desde el noroeste. Pintura de tradición esquemática de Pala de Cabras (Ourense) en el VII Congreso Internacional sobre el Neolítico en la Península Ibérica celebrado en Sevilla entre el 29 de Enero y el 1 de Febrero de 2020. que discurre el arroyo de San Xil. Se trata de un conjunto montañoso de valles encajados y laderas escarpadas situado en las estribaciones occidentales da la Serra do Eixe en el Macizo de Pena Trevinca, que divide las provincias de Ourense, Zamora y León. El río de San Xil recorre un angosto valle de unos $10 \mathrm{~km}$ de longitud orientado SSE-NNW. El yacimiento arqueológico se encuentra al norte del mismo, en su margen derecha. (Fig. 1)

El abrigo se sitúa en un contexto geológico de cuarcitas blancas armoricanas del período Ordocívico. El entorno está formado por un espeso bosque de especies como el roble, tejo, abedul, acebo o aliso común. El espacio circundante está deshabitado en la actualidad. Uno de los aspectos a destacar, en relación al contexto arqueológico del abrigo, es la ausencia en el valle de evidencias arqueológicas prehistóricas; los castros más cercanos se sitúan a $3 \mathrm{~km}$. de distancia en las cercanías de la población de Casaio y los túmulos prehistóricos más próximos se localizan a $6 \mathrm{~km}$, siempre fuera del valle.

El ayuntamiento de Carballeda de Valdeorras, y concretamente el entorno de Casaio, es rico en minas de pizarra e históricamente destacó por las explotaciones de wolframio durante la Segunda Guerra Mundial, contando además con algunas áreas con vetas de hierro y de cobre.

\section{Descripción del abrigo y de las pinturas}

Debido a lo escarpado del relieve, con pendientes en torno al $60 \%$ de inclinación en las laderas del valle de San Xil, el acceso al abrigo presenta ciertas dificultades. Por otro lado, las mismas laderas de las montañas y lo angosto del valle, provocan que Pala de Cabras tenga una visibilidad sobre el entorno muy reducida, en la que únicamente caben algunos sectores del valle en el que se encuentra y una parte de Pena Trevinca. (Fig. 2)

El abrigo posee una amplia abertura de 30 $\mathrm{m}$. de ancho, $10 \mathrm{~m}$ de fondo y una altura máxima que varía entre los 6 y 7 metros. En la entrada del abrigo destaca la presencia de una cascada, cuya corriente cae al vacío desde la parte superior, alimentada por un riachuelo que desciende por la ladera y que suele secarse en época estival. La mayor parte del suelo presenta el sustrato pétreo descubierto, por lo que carece de acumulación de depósitos que pudieran albergar estratos arqueológicos. Sin embargo, en 


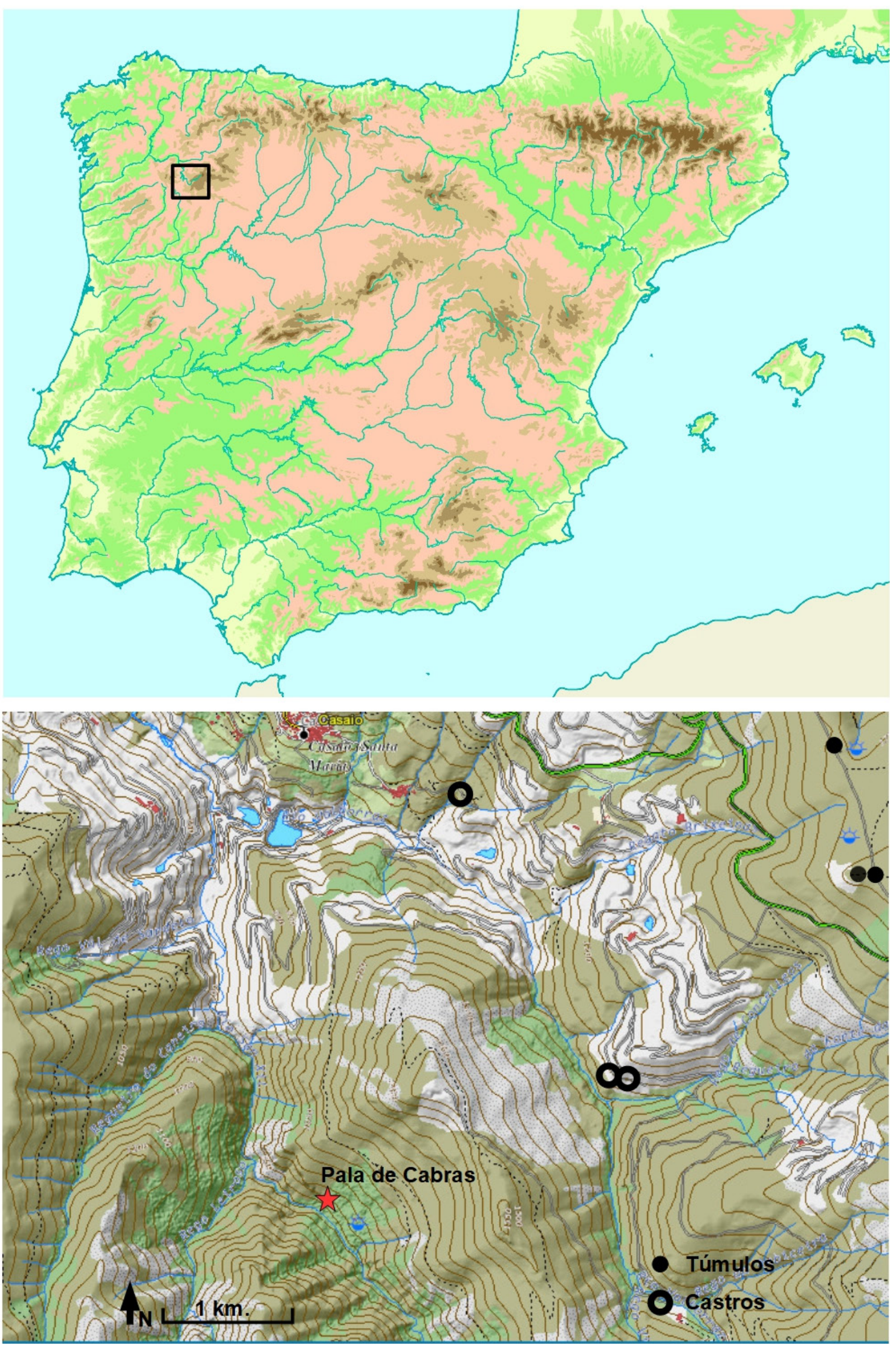

Fig. 1. Localización del abrigo de Pala de Cabras y contexto arqueológico. 


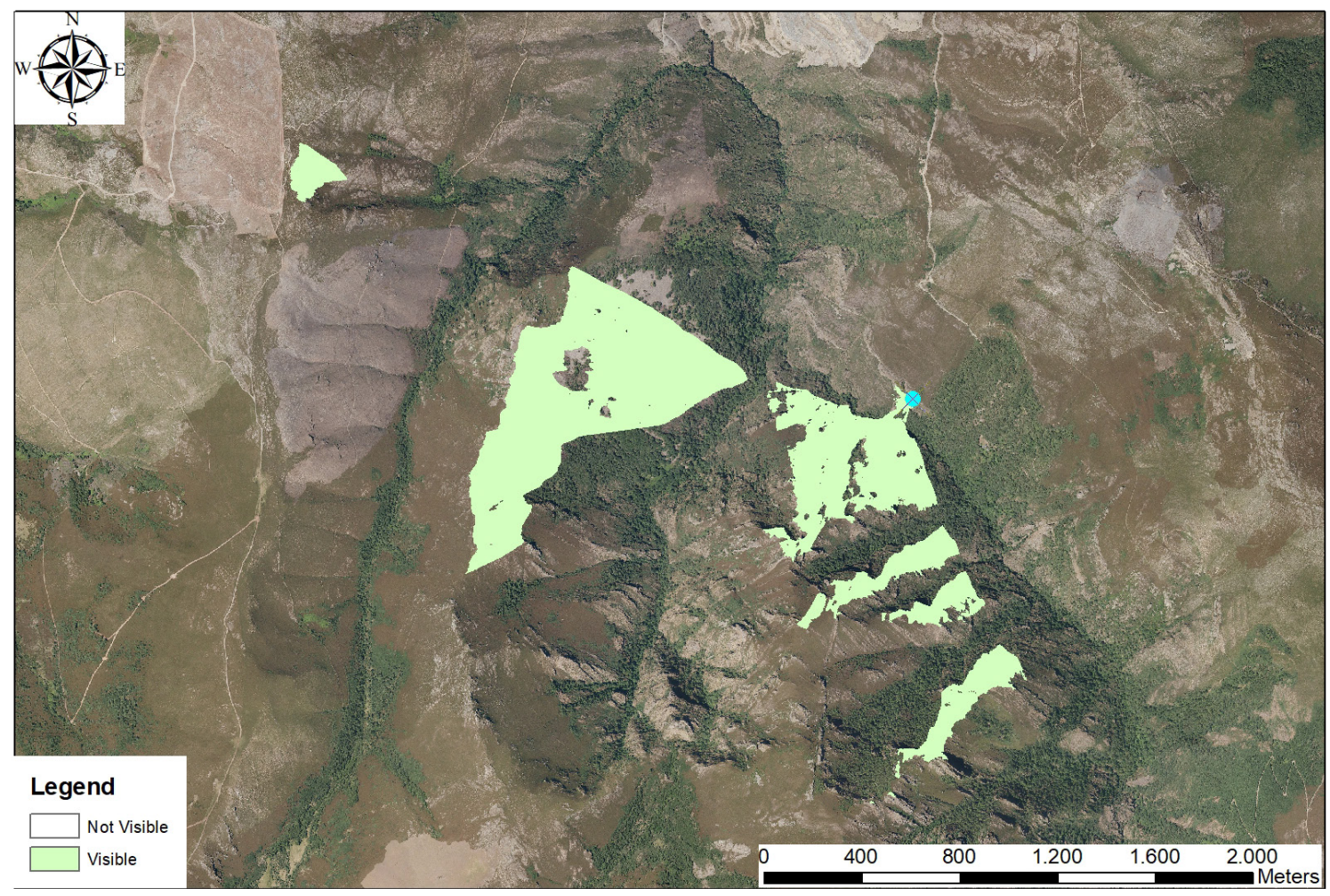

Fig. 2. Visibilidad desde Pala de Cabras.

su extremo meridional, lugar en el que se encuentra la choza de la guerrilla, se conservan depósitos de tierra susceptibles de ser excavados arqueológicamente. Se desconoce en qué medida la construcción de esta choza pudo haber alterado los depósitos subyacentes y si estos pueden contener material arqueológico anterior a 1936. El suelo del abrigo presenta una superficie irregular con una inclinación de unos $20^{\circ}$ en términos generales, que desciende desde su parte más alta en el norte hacia la parte más baja en el sur. La cavidad presenta una superficie predominantemente cuarcítica muy fragmentada en sus paredes, suelo y techo, aunque recoge otras formaciones geológicas complementarias, entre las que cabe destacar una arenisca muy degradada que conformaría parte del suelo. La pared oriental está cubierta por musgos y por óxidos de arsenopirita de color blanquecino ${ }^{6}$, que no permite observar la superficie de la roca y confirmar o descartar la existencia de más pinturas. En el suelo, el techo y en las paredes meridionales no han sido detectados pigmentos, por lo tanto, la única zona del abrigo en el que se documenta arte rupestre es en la pared norte.

6 La posible presencia de este óxido de arsenopirita fue señalada, tras una inspección ocular del sitio, por el geólogo José Fernández Pérez a quien agradecemos la información.
Las pinturas se sitúan allí donde son más abundantes las superficies lisas y verticales. (Fig. 3)

La fragmentación que presentan las paredes del abrigo, ha generado una sucesión de superficies verticales divididas por grietas y cambios en la orientación de las paredes, que han servido para dividir las pinturas en 15 paneles que, para su descripción, serán numerados de oeste a este, es decir, desde la entrada hacia el interior (Fig. 4). Así mismo, dichos paneles se disponen a dos alturas distintas siguiendo la disposición natural de las grietas que definen dos pisos de paneles que vamos a denominar de forma figurada "frisos". La altura a la que se sitúan los dos frisos respecto al suelo oscila entre los 0,8 y los $2,1 \mathrm{~m}$.

Todas las pinturas presentan diferentes tonos rojizos. Prácticamente todos los paneles se encuentran parcialmente conservados, por lo que, si bien en algunos casos es posible definir la iconografía o el signo representado, en otros únicamente se observa algún trazo insuficiente para identificar algún motivo concreto, incluso en algún caso, la presencia de pintura no permite asegurar si se trata de trazos realizados intencionalmente o de simples manchas de pigmento.

Siguiendo el mencionado orden de oeste a este, es decir, desde la boca del abrigo hacia el interior, han sido definidos 15 paneles que pasamos a describir: 


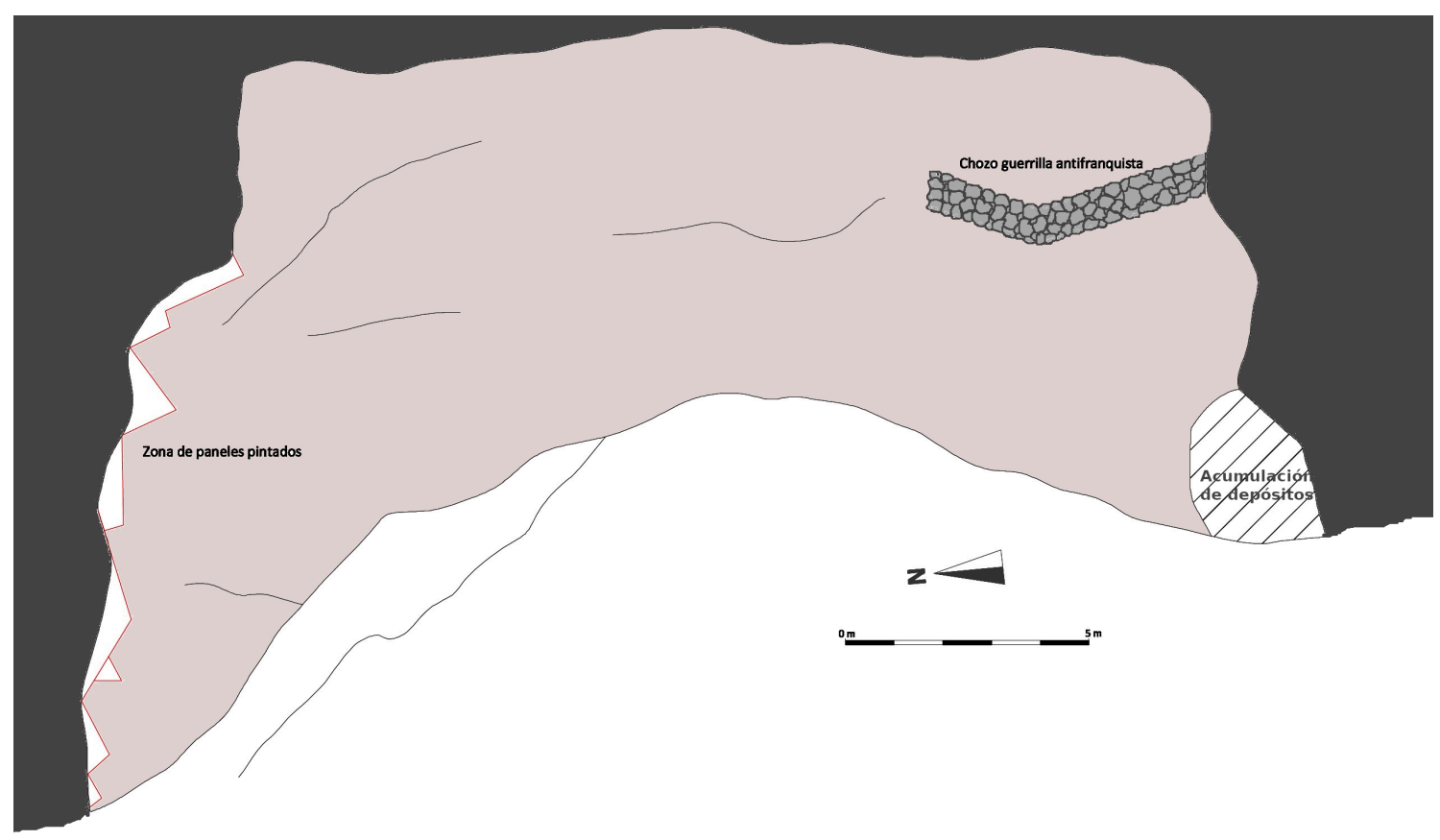

Fig. 3. Planta del interior del abrigo de Pala de Cabras.

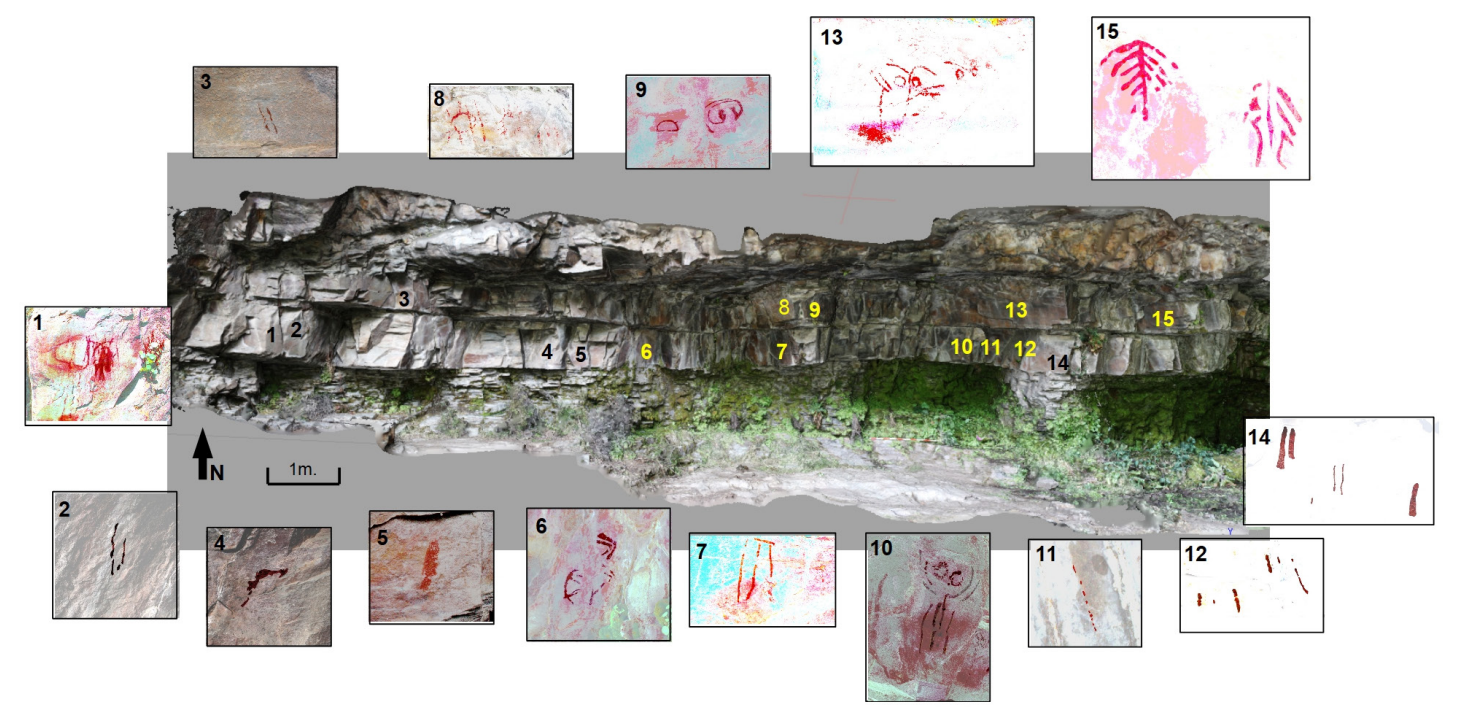

Fig. 4. Fotogrametría de la pared norte del abrigo con la distribución de los paneles.

Panel 1: localizado en el extremo oeste de la pared norte del abrigo. Se sitúa en la primera superficie vertical parcialmente protegida por el techo del abrigo en el friso inferior. Presenta varias figuras. Una de ellas se trata de una figura con tendencia hacia una forma circular; a su lado aparecen diversos trazos predominantemente verticales junto a varias masas de color de dificil lectura e interpretación que podrían pertenecer al mismo motivo. Atravesando verticalmente la figura circular y prolongándose hacia la parte inferior del panel, existen dos líneas discontínuas paralelas. La pintura ocupa una superficie de 20 $\mathrm{cm}$ de ancho por $12 \mathrm{~cm}$ de alto. (Fig. $5 \mathrm{a}, \mathrm{b}$ )

En la parte inferior del panel se puede observar una línea vertical negra. Posiblemente fue realizada con carbón en seco. Desconocemos la cronología de la misma y, por lo tanto, si pertenecería a la iconografía original o es un añadido más reciente. 

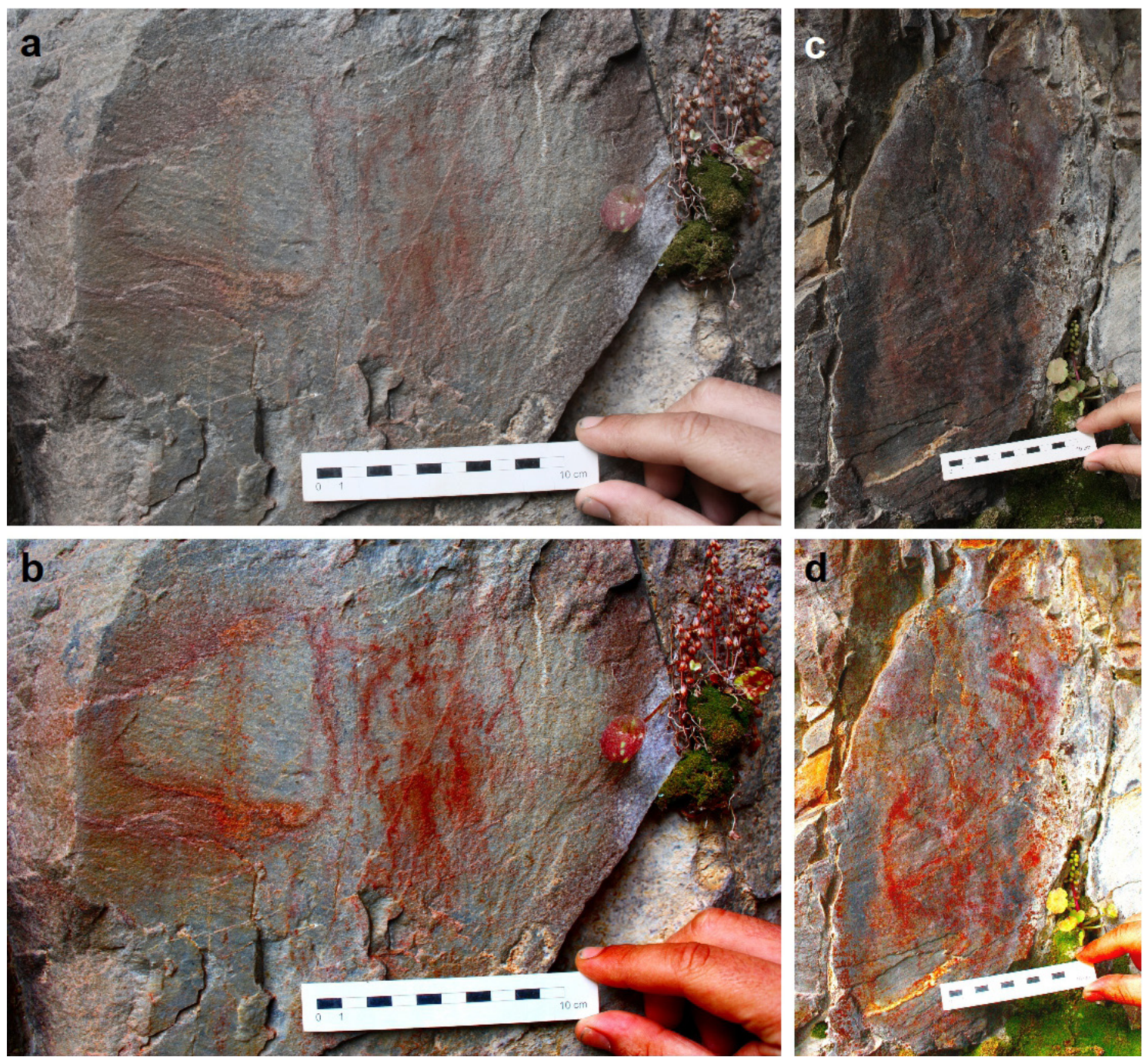

Fig. 5. a) fotografía del panel 1; b) imagen del panel 1 tratada con el programa DStretch; c) fotografía del panel 6; d) imagen del panel 6 tratada con DStretch.

Panel 2: se sitúa en la superficie contigua y al este de la anterior. El panel está formado por varias líneas verticales irregulares y ligeramente ondulantes de unos $11 \mathrm{~cm}$ de longitud. Esta pintura se encuentra sobre una superficie rugosa, circunstancia esta infrecuente en el abrigo, puesto que todas las demás pinturas tienden a situarse en superficies lisas. No se puede descartar que se trate de pintura, más que aplicada, derramada sobre la pared.

Panel 3: está situado en el friso superior a 1 metro al este del panel 2. Presenta dos líneas rojas paralelas, casi verticales, de unos $5 \mathrm{~cm}$ de longitud.

Panel 4: situado en el friso inferior a 1,90 $\mathrm{m}$ al este del anterior. En una superficie ligeramente rugosa, presenta una línea simple que forma un ángulo de 90 grados. Posiblemente se trate de los restos de una figura más compleja, que en la actualidad se halla casi desaparecida.

Panel 5: situado en una superficie contigua al panel 4, presenta diversas grietas y fracturas horizontales. En la parte inferior derecha aparece una mancha rojiza vertical de $6 \mathrm{~cm}$ de largo y $1 \mathrm{~cm}$ de ancho a modo de barra, $10 \mathrm{~cm}$ más arriba, aparece otra diminuta mancha de tonalidad semejante a la anterior.

Panel 6: situado a $0,40 \mathrm{~m}$ al este del panel $5 \mathrm{y}$ en el mismo friso. Se puede observar un trazo, muy posiblemente un zig-zag doble. A la izquierda de este diseño, existen restos de otra figura parcialmente borrada. No resulta fácil concretar cual sería la forma completa de esta segunda figura, aunque cabe la posibilidad de que se trate de un círculo segmentado radialmente o bien algún tipo de diseño formado por figuras triangulares (Fig. 5 c, d). 
Panel 7: se encuentra a 3,50 $\mathrm{m}$ al este del panel 6. Presenta dos figuras. En la parte superior del panel se observa un pectiniforme formado por tres líneas verticales, paralelas y unidas en su extremo superior a una línea horizontal. La figura tiene $12 \mathrm{~cm}$ de alto y $7 \mathrm{~cm}$ de ancho. En la parte inferior derecha aparece un trazado vertical de unos $7 \mathrm{~cm}$ de longitud. (Fig. 6 a,b)
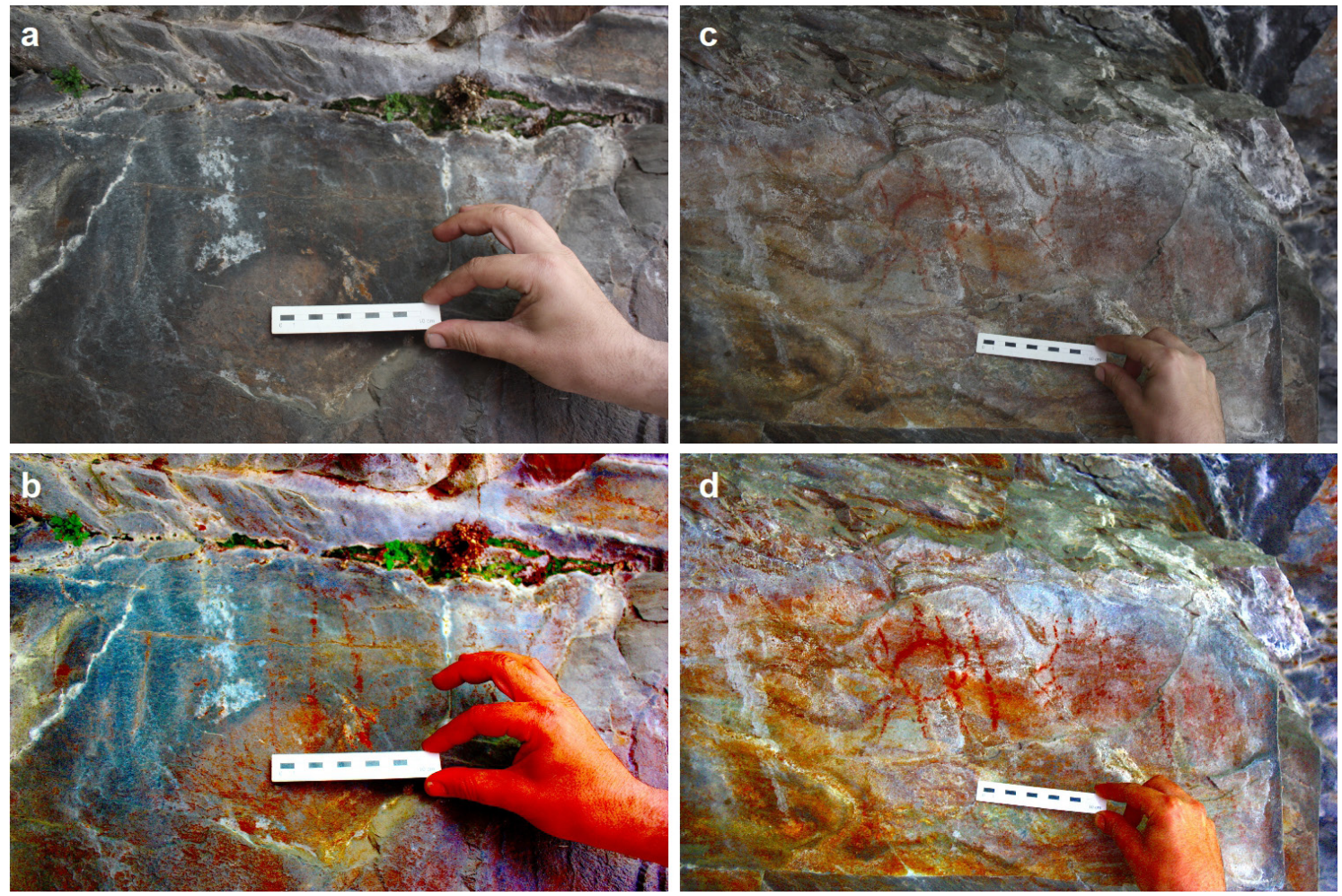

Fig. 6. a) fotografía del panel 7; b) imagen del panel 7 tratada con el programa DStretch; c) fotografía del panel 8; d) imagen del panel 8 tratada con DStretch.

Panel 8: situado en una superficie inmediatamente superior a la del panel 7. Presenta dos soliformes formados por dos círculos con diversas líneas que parten del perímetro de dichos círculos en disposición radial. La figura de la izquierda se completa con la presencia de un trazo vertical que la atraviesa por completo. Entre ambos soliformes aparece una línea vertical. A la derecha de los soliformes existe una figura formada por tres líneas verticales paralelas y una horizontal formando un diseño pectiniforme muy semejante al descrito en el panel 7. Bajo esta última figura, se observan varias líneas de dificil interpretación debido a la mala conservación de las pinturas. La composición completa ocupa una superficie de 27 $\mathrm{cm}$ de ancho por $24 \mathrm{~cm}$ de alto. (Fig. 6, c,d)

Panel 9: se localiza en el panel contíguo y a la misma altura que el panel 8. Presenta dos óvalos de $5 \mathrm{~cm}$ de ancho y 7 y $5 \mathrm{~cm}$ de largo respectivamente. Las figuras están muy desvanecidas, por lo que se encuentran parcialmente desaparecidas y su lectura resulta muy dificil. (Fig. 7 a, b)

Panel 10: se encuentra a $1,60 \mathrm{~m}$ al este del panel 9 y en el friso inferior. Presenta una figura de las denominadas oculadas o ídolos oculados. Los ojos se definen por la disposición de numerosas líneas cortas dispuestas radialmente y aparecen enmarcados por dos líneas arqueadas concéntricas. La figura se completa con cuatro líneas verticales y aproximadamente paralelas situadas bajo el rostro que acabamos de describir. La figura completa tiene 21 $\mathrm{cm}$ de altura por $13 \mathrm{~cm}$ de ancho. (Fig. $7 \mathrm{c}, \mathrm{d}$ )

Panel 11: se sitúa en la superficie contigua al panel 10. En el lado derecho, se observa una única línea vertical discontinua precariamente conservada. Este trazo mide unos $8 \mathrm{~cm}$ de longitud.

Panel 12: situado al este del panel 11, en una superficie vertical localizada en el friso inferior. Presenta al menos 5 líneas verticales, a modo de barras, con un grosor en torno a 1 
$\mathrm{cm}$ y de longitud variable entre 2 y $13 \mathrm{~cm}$. Varias de estas líneas se agrupan formando pares paralelos y yuxtapuestos. Pudieran existir más figuras, pero la lectura resulta difícil debido a la profusa presencia de manchas blanquecinas que cubren parte de la superficie del panel.
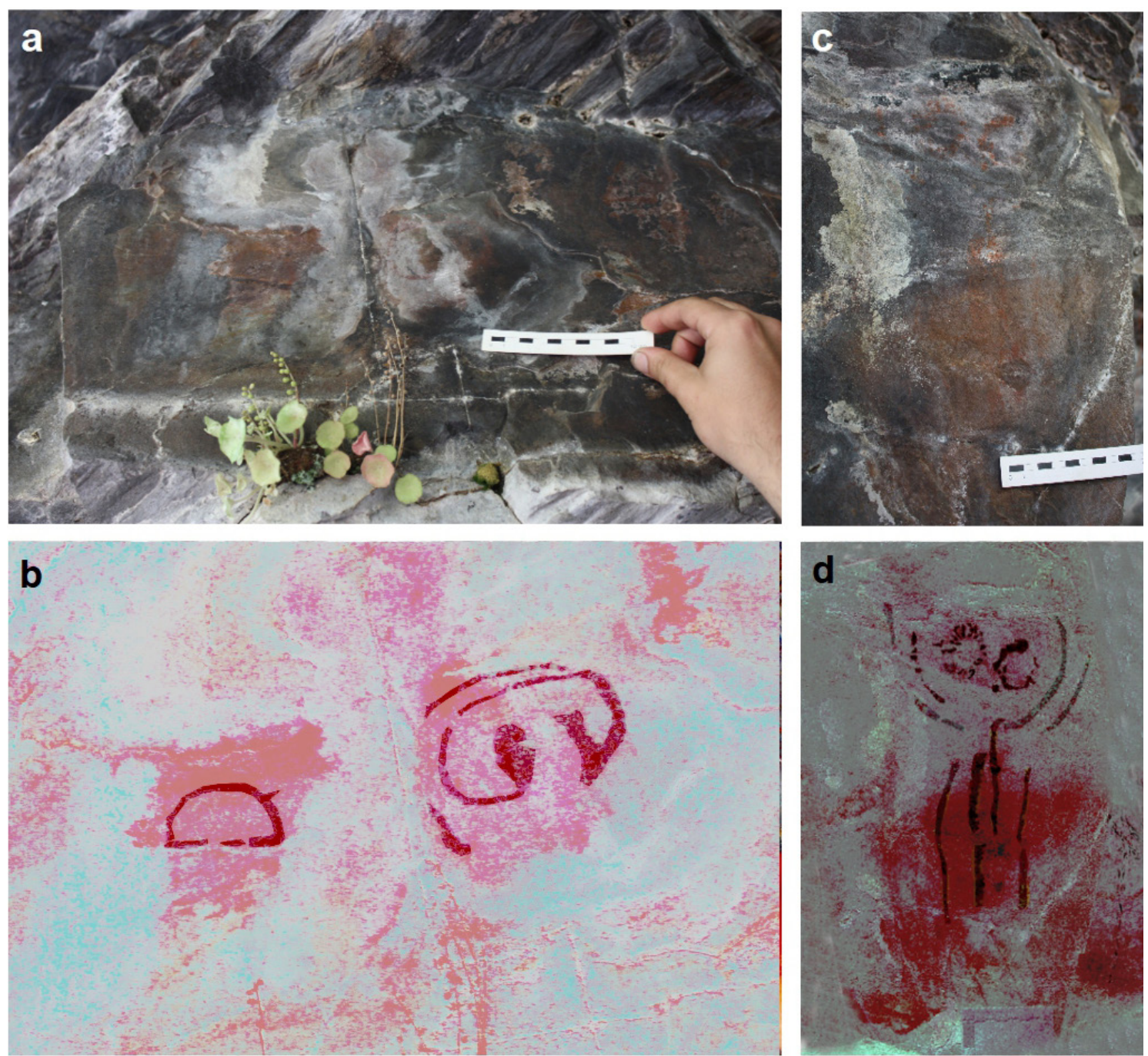

Fig. 7. a) fotografía del panel 9; b), calco del panel 9 realizado sobre imagen tratada con DStretch; c) fotografía del panel 10; d) calco del panel 10 realizado sobre imagen tratada con DStretch.

Panel 13: localizado en el friso superior en una superficie situada sobre el panel 12. La iconografía de este panel está formada por 2 figuras oculadas. La de la izquierda está mejor conservada, presenta los dos ojos formados por sendos círculos simples, tiene dos arcos supraciliares o cejas que convergen entre los ojos y se prolongan verticalmente formando lo que podría ser la nariz y el tronco. Bajo cada uno de los ojos tiene dos líneas paralelas, elementos que suelen ser interpretados como escarificaciones o pinturas faciales. A la derecha de esta figura, se observan dos círculos simples y parte de lo que pudieran ser las cejas de una segunda figura oculada incompleta. La primera figura mide $17 \mathrm{~cm}$ de alto por 15 de ancho. La segunda figura mide 7 por $5 \mathrm{~cm}$ (Fig. $8 \mathrm{a}, \mathrm{b}$ )

Panel 14: situado en la superficie contigua al panel 12. Presenta 6 barras verticales, tres de ellas de $1 \mathrm{~cm}$ de grosor y las otras tres de $0,2 \mathrm{~cm}$ Las longitudes oscilan entre los 9 y $\operatorname{los} 2 \mathrm{~cm}$. Varias de las líneas se agrupan formando pares de barras paralelas y yuxtapuestas.

Panel 15: situado a $1,20 \mathrm{~m}$. al este del panel 14, en el friso superior. Presenta dos figuras de las denominadas ramiformes, ambas formadas por una línea vertical de la que parten entre 4 y 6 líneas oblícuas des- 
cendentes. La figura de mayor tamaño mide $17 \mathrm{~cm}$ de alto por 9 de ancho y la menor 14 de alto por 7 de ancho. Tal y como sucede con la práctica totalidad de los paneles, las
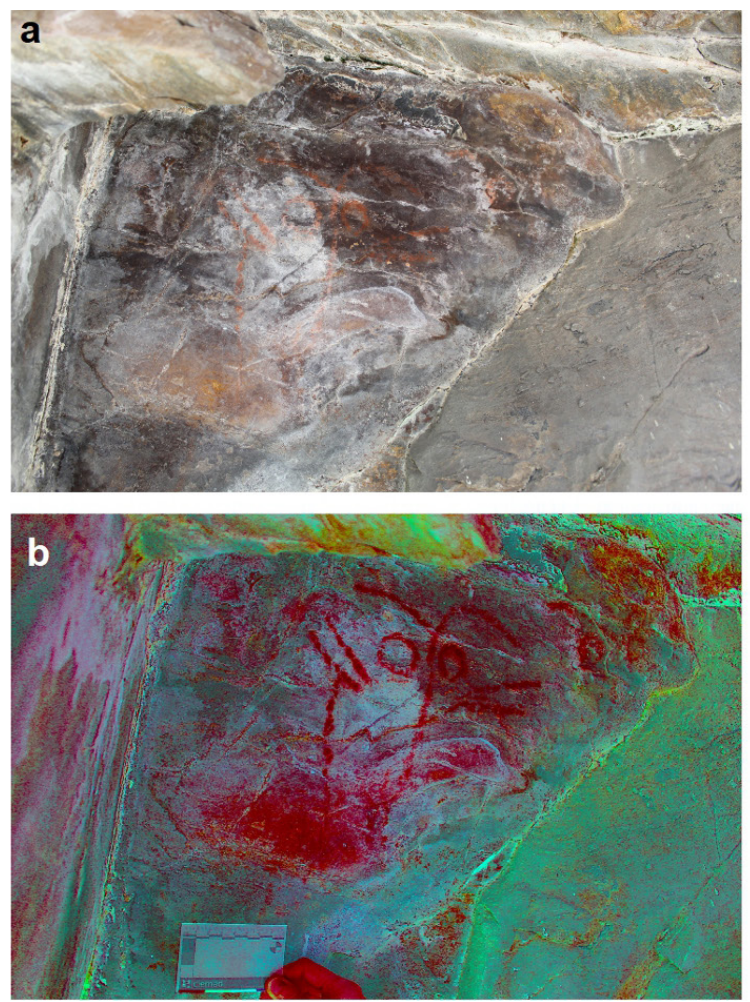

Fig. 8. a) fotografía del panel 13; b) imagen del panel 13 tratada con el programa DStretch; c) fotografía del panel 15; d) calco del panel 15 realizado sobre imagen tratada con el programa DStretch.

\section{Estado de conservación de las pinturas}

La mayor parte de las pinturas están en un mal estado de conservación y, en casi todos los casos, la observación de las mismas resulta muy difícil sin ayuda de una tecnología de tratamiento digital de la imagen, en este caso ha sido aplicada el programa Dstretch. La práctica totalidad de los paneles parecen haber perdido al menos una parte de los pigmentos, algunos de ellos solamente conservan unas pocas líneas o manchas de lo que debió ser una composición más compleja, como sería el caso de los paneles 2, 3, 4 y 11 . En otros casos se conserva una mayor cantidad de pintura, pero resulta dificil identificar el tipo de motivo que está representado, como es el caso de los paneles 1 y 9. Finalmente, en los casos mejor conservados, aunque sí es posible identificar los motivos, las figuras están incompletas, estos serían los casos de las barras de los paneles 5, 12 y 14, el zigzag del 6, los pectiniformes del 7 y 8 , los soliformes en el 8,

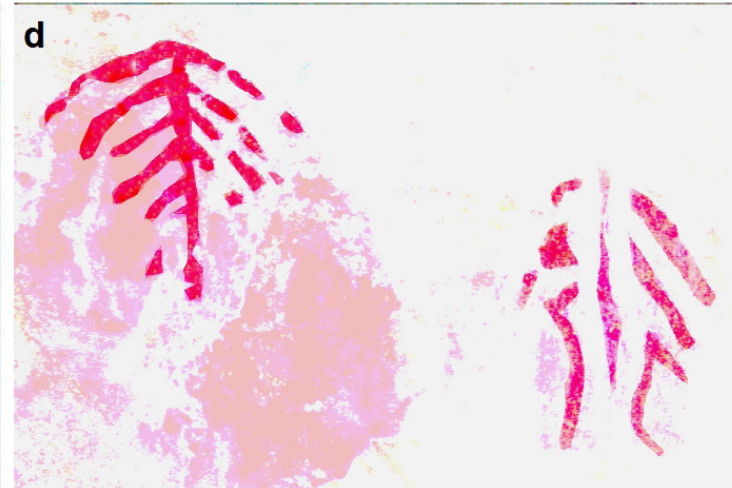

figuras aparecen incompletas, bien por haber desaparecido la pintura bien por estar cubiertas por manchas blanquecinas. (Fig. $8 \mathrm{c}, \mathrm{d}$ )

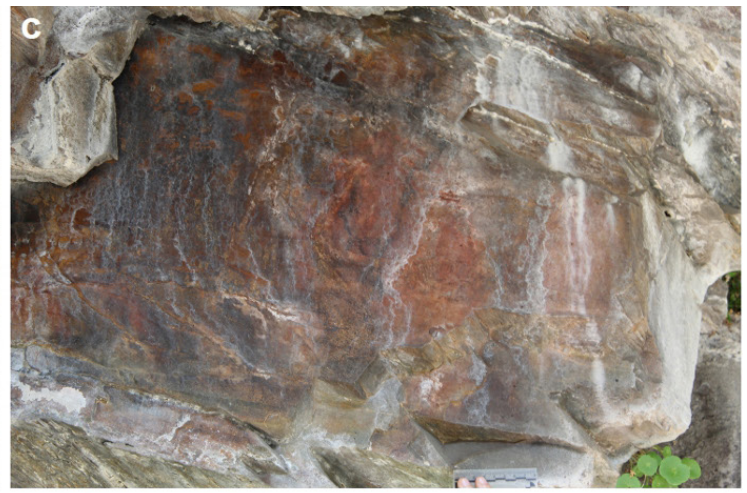

las figuras oculadas del 10 y 13 y los ramiformes del panel 15. En todo caso, no podemos descartar que en la pared norte, hubiesen existido más paneles con pinturas de las que en la actualidad nada se conserva. Es probable que en los espacios sin decoración comprendidos entre los paneles 3 y 4, 6 y 7, 9 y 10, hubiese más pinturas, habida cuenta de la presencia de superficies verticales y lisas con las mismas características que las que actualmente presentan diseños.

También debemos señalar la presencia de manchas blanquecinas, muy probablemente óxidos de arsenopirita, que impiden la observación de parte de los paneles más alejados de la entrada del abrigo, especialmente de los paneles 12, 14 y 15. En términos generales, la presencia de dichas manchas es más profusa en las superficies más interiores del abrigo, siendo ya de cobertura total en el lado oriental, donde se localizan las superficies más alejadas de la entrada y más afectadas por filtraciones y por la humedad. 
Por otra parte, llama la atención que el panel 1 haya conservado la pintura hasta la actualidad, teniendo en cuenta que el agua de la lluvia debe llegar con cierta frecuencia, especialmente cuando ésta se da con viento de componente oeste y sudoeste, que suele ser el más asociado al tiempo húmedo.

Es todavía una tarea por realizar el análisis de los agentes que pueden estar afectando a la conservación de las pinturas que, por lo apuntado en relación al panel 1 , no parece que sea la mayor o menor exposición a meteoros tales como la lluvia, sino más bien pueden estar relacionados con otro tipo de procesos, que futuros estudios deberán dilucidar.

1

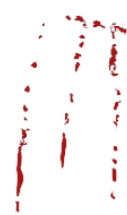

2

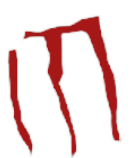

Valoración general de las pinturas y su cronología

En definitiva, los diseños representados en Pala de Cabras conforman un conjunto de paneles con una distribución general horizontal, repartidos en dos alturas a modo de frisos y que se encuentran por encima de la altura de la vista de cualquier observador que se encuentre en el interior del abrigo. Desde el punto de vista iconográfico, centraremos nuestro análisis en aquellos paneles con el suficiente grado de conservación que permita la identificación de los motivos representados, estos son los paneles $6,7,8,10,13$ y 15. (Fig. 9)

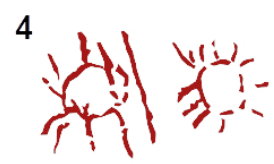

5

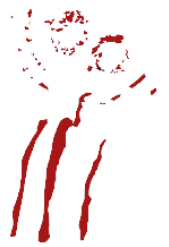

3

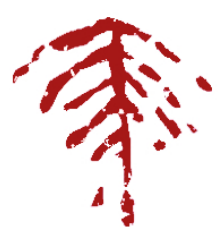

6

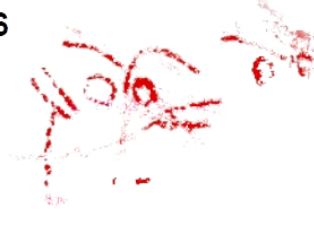

Fig. 9. Selección de motivos de Pala de Cabras. 1, pectiniforme del panel 8. 2. pectiniforme del panel 7. 3 ramiforme del panel 15. 4, soliformes del panel 8. 5, oculado del panel 10 y 6 , oculados del panel 13 .

El panel 6 presenta dos figuras geométricas, la situada a la izquierda es la de más difícil lectura, que como ya quedó apuntado en su momento, podría tratarse de un círculo segmentado, diseño presente en algunos grabados rupestres del noroeste ibérico. Sin embargo la de la derecha presenta un diseño en zigzag doble. Esta figura en zigzag vertical, guarda una evidente similitud con diversas representaciones del Arte Esquemático ibérico, aunque un ejemplo cercano lo tenemos en el abrigo de Cova dos Mouros en el ayuntamiento de Baleira, Lugo (Rodríguez Rellán et al. 2019). Así mismo, además de la presencia de los zigzag verticales múltiples en el Arte Esquemático, también están presentes en megalitos del noroeste peninsular, como por ejemplo en Pedra Cuberta (Vimianzo, A Coruña) o Monte dos Marxos, (Rodeiro, Pontevedra) por lo que podríamos apuntar como cronología más probable en tor- no al V y IV milenio a. C. (Carrera Ramírez y Fábregas Valcarce 2002).

Los pectiniformes de los paneles 7 y 8 encuentran numerosos paralelos en el Arte Rupestre Esquemático, tanto grabado pero sobre todo, pintado. No obstante, para encontrar figuras semejantes, es decir, diseños con el eje vertical sensiblemente mayor que el horizontal y formados únicamente por tres líneas, debemos buscarlas en la Cueva de la Murcielaguina (Córdoba), donde han sido interpretados como la representación de un rostro humano debido a la presencia de dos puntos a modo de ojos (Barroso Ruíz 1983), o como el caso de la estela asociada a un megalito en Chao do Brinco en Viseu (Silva 1993) denominado por Bueno y Balbín (1996) como un rostro en T. La diferencia con los ejemplos de Pala de Cabras es la carencia de las posibles representaciones de ojos. 
En el panel 8 también podemos destacar los dos soliformes. Este tipo de figuras parecen tener un amplio desarrollo cronológico, habida cuenta de que su presencia ha sido documentada en la cerámica cardial, así como en la cerámica simbólica. Por lo tanto su cronología podría abarcar desde el Neolítico Antiguo hasta el Calcolítico. Se trata de un tipo de representación que sigue criterios estéticos muy extendidos y dificilmente encuadrables en un periodo concreto, por lo que, tal y como aparecen representados en Pala de Cabras, no es posible precisar demasiado su cronología. Podemos situarlos entre esos dos marcos relativos a la mencionada cerámica, es decir, entre el VI/V milenios hasta el III milenio a. C.

El panel 15 presenta dos motivos ramiformes. Este tipo de diseño es también muy común en el Arte Esquemático, aunque la mayoría de estas representaciones presentan las ramas en posición horizontal o en diagonal orientados con el extremo hacia arriba o formando un ángulo inicialmente hacia arriba y luego descendente a semejanza de algunas plantas de cereal. En el caso que nos ocupa, las ramas aparecen inclinadas hacia abajo a modo de arboriforme muy poco común, pero que puede ser observado en algún caso del arte postpaleolítico en el Risco de San Blas de Albuquerque (Collado 1997), en el Covacho del Cubilejo y en el Abrigo del Mirador (Gómez-Barrera 2001) o en la Cueva de Pileta (Málaga) designado como ramiforme en espiga (Sanchidrián Torti y Muñoz Vivas 1990). Así mismo, los motivos representados en el Abrigo de los Ingenieros II de Nerpio (Albacete) muestran una idéntica tipología (García Guinea 1963).

Finalmente, en los paneles 10 y 13 tenemos tres representaciones de los denominados ídolos o figuras oculadas. Aunque este tipo de figuras ofrecen cierta variedad formal en el arte rupestre penínsular, las representaciones más complejas, es decir, aquellas que presentan además de los dos ojos, los arcos supraciliares y dos o más líneas paralelas bajo los ojos, se encuentran casi todas al sur del Guadalquivir así como en la zona de las cuencas del Segura y del Júcar (Becares 1990; Soria et al. 2013), con una única excepción, la de Regato das Bouças (Tras-os-Montes) (Sanches et al. 2016). Así mismo, respecto a este tipo de figuras, existe coincidencia en encuadrarlas cronológicamente desde los primeros trabajos de $\mathrm{H}$. Breuil (1935) o P. Acosta (1984), así como en trabajos más recientes (Hurtado 2008; García
Atienzar 2006; Maicas Ramos 2010) en el III milenio a. C. Respecto a los casos concretos de Pala de Cabras, debemos decir que no guardan mayores semejanzas con las representaciones más cercanas geográficamente. Para el ejemplar mejor conservado del panel 13 encontramos una figura muy similar en Cantos de la Visera (Murcia) (Barroso 1983). Sin embargo, para el caso del panel 10, debemos llamar la atención sobre el hecho de que la forma en que fue ejecutada, es muy poco común en arte rupestre. La forma de diseñar los ojos, a base de numerosas líneas en disposición radial dejando un espacio circular en su interior y la forma de diseñar las líneas ovaladas concéntricas que rodean parcialmente los ojos, son más propias de representaciones en objetos muebles ${ }^{7}$, especialmente cilindros, que de la Pintura Esquemática.

Existe cierta coincidencia entre los diferentes especialistas en situar el Arte Rupestre Esquemático de la Península Ibérica en un marco cronológico con sus límites máximos entre el Neolítico Antiguo (VI-V milenio a. C.) hasta la Edad del Bronce, pudiendo prolongarse hasta la transición hacia la Edad del Hierro, en los inicios del I milenio a. C. Siendo el momento de mayor producción entre el VI y V milenios hasta la primera mitad del II milenio a. C. (Acosta 1968, 1984; Carrasco y Pastor 1983, Sanches 1997, Martínez García 2002, Hernández Pérez 2006). Mauro Hernández (2006) distingue dos períodos para el desarrollo de este grupo de arte. La fase más antigua precedería al Megalitismo y podría encuadrarse en el Neolítico Antiguo. Los diseños más característicos consistirían en antropomorfos en Y, doble Y y X, ramiformes, esteliformes y zigzags. Algunos de estos motivos podrían ser identificados en soportes muebles como cerámica y cantos rodados coetáneos, como los documentados en la Cueva de Chaves en Huesca (Utrilla y Baldellou 2002) y encuadrables en el Neolítico Antiguo.

La segunda fase de desarrollo del Arte Esquemático presentaría en principio, una menor dificultad en cuanto a su definición, distribución y, por lo tanto, en cuanto a su cronología. Este grupo sería contemporáneo del Megalitismo. Los motivos más característicos son los ídolos representados en diversas formas.

Quizás se podría mencionar la posible figura oculada presente en el desaparecido vaso tetralobulado de Buriz (Guitiriz, Lugo) (Vázquez Varela 1996). 
Estas figuras idoliformes están estrechamente emparentadas con las asociadas a la Cultura de Los Millares con antropomorfos oculados y bitriangulares fundamentalmente. En este sentido hay que destacar los estudios de Julián Martínez (2002) respecto a la estructuración de los paneles esquemáticos, que suelen mostrar patrones distributivos más evidentes en la fase que algunos autores consideran más tardía y una distribución más anárquica en las más antiguas, lo que parece confirmar una neta diferencia entre estos dos períodos.

Por otro lado, Hipólito Collado (2006), propone una división cronológica semejante, aunque añade un patrón de localización para cada una de estas dos divisiones. Los motivos que se corresponderían con el inicio del ciclo de Arte Esquemático serían los ondulantes múltiples, también presente en el Arte Macroesquemático, y diseños muy semejantes a los observables en decoraciones de cerámicas cardiales, como los antropomorfos en actitud "orante", antropomorfos en Y y doble Y, zigzag simple $\mathrm{y}$ en paralelo, ramiformes, soliformes, aunque estos últimos podrían tener una vigencia que se extendería durante el Calcolítico y la Edad del Bronce. Collado propone para esta fase una cronología del Neolítico Antiguo, relacionada, entre otros items, con la cerámica cardial, que para Extremadura podría situarse en torno al VI milenio a. C. Así mismo, los abrigos con este tipo de representaciones presentan en dicha región una organización en paneles de tamaño reducido y con un número escaso de figuras. La posición en el relieve de los yacimientos de esta primera etapa del Neolítico, es poco destacada, por ejemplo, se sitúan en alineaciones serranas, junto a las orillas de las quebradas de los ríos o en una llanura salpicada de bloques graníticos. En definitiva, estos abrigos no se articulan como un elemento de referencia en el paisaje (Collado Giraldo 2006: 297-298).

Si volvemos nuestra mirada hacia Pala de Cabras, veremos que presenta algunas de las características propias de abrigos con el Arte Esquemático que Hernández, así como Collado, sitúan en el Neolítico Antiguo. Por un lado, algunos de los motivos como zigzags dobles y ramiformes; por otro, la forma de organizar la decoración en paneles pequeños con escaso número de motivos, generalmente entre 1 y 3 motivos por panel y, finalmente, el emplazamiento en la ladera de un angosto valle en una posición muy poco destacada, podrían corres- ponderse con esa fase más antigua del Arte Esquemático. Sin embargo, no podemos obviar la presencia de motivos más tardíos, como son las figuras oculadas, situadas cronológicamente entre el Neolítico Tardío y la Edad del Bronce, siendo el Calcolítico el período de mayor producción de estas figuras, al menos en sus representaciones en soportes muebles.

Teniendo en cuenta la información disponible, posiblemente Pala de Cabras pudo haber empezado a albergar las primeras pinturas en el Neolítico Antiguo. El abrigo debió estar en funcionamiento como espacio sagrado con un valor simbólico acumulado durante un prolongado período de tiempo, que se extendería hasta por lo menos el III milenio a. C., momento en el que habrían sido añadidas más pinturas, entre las que se encontrarían las figuras oculadas.

\section{Pala de Cabras en el contexto del Arte Esquemático del noroeste ibérico}

La documentación del Arte Rupestre Esquemático en el noroeste de la Península Ibérica, entendiendo esta región como la comprendida entre el río Duero al sur y el Esla al este, no es reciente. En Portugal encontramos, no solamente las primeras referencias sobre Arte Esquemático de la Península Ibérica, sino una de las primeras documentaciones de arte rupestre a nivel mundial, como es Cachão da Rapa (Bragança) publicado por J. Contador de Argote en la primera mitad del siglo XVIII. Pero será a partir del siglo XX, cuando se sucedan los descubrimientos y catalogaciones sistemáticas a partir de la publicación de Pala Pinta (Vila Real) por H. Mesquita (1922). A partir de los años 70 se intensifican los trabajos que han permitido definir una importante región en lo que a esta tradición rupestre Esquemática se refiere; así, en 1977, son descubiertas las pinturas del Portillón y de Melendro en Zamora (Grande del Brío 1982). En la misma provincia es documentado el abrigo de Castillón y publicado en 1987 por Fernández Rivera, aunque era conocido desde hacía varias décadas. Por otra parte en Asturias, desde los inicios de los años 80 , se publican las pinturas de la Cueva del Demo en el valle del Navia (Blas Cortina y Carrocera Fernández 1985). Peña Piñera (León) es identificada en 1982 (Gutiérrez González y Avello Álvarez, 1986). Actualmente, en la región comprendida entre en Duero y el Esla, se conocen unos 34 conjuntos de pintura y grabados rupestres Esquemáticos. 
El conjunto iconográfico de Pala de Cabras es uno de los más complejos de los documentados hasta el momento en el noroeste de la Península Ibérica con 15 paneles y 25 motivos. Entre los diseños presentes en el abrigo podemos citar algunos de los más representativos del Arte Esquemático, como son las barras verticales (paneles 5, 12 y 14), los pectiniformes (paneles 8 y 7), soliformes (panel 8), figuras oculadas (paneles 10 y 13) y ramiformes (panel 15). Sin embargo, llama la atención la ausencia de motivos tan caraterísticos del Arte Esquemático tanto del Noroeste como del resto de la Península, como son los puntos y sobre todo, las representaciones esquemáticas de antropomorfos, aunque no podemos descartar que dicha ausencia sea debida a problemas de conservación. No obstante, tal y como hemos mencionado, el abrigo presenta otros motivos tan característicos como son los pectiniformes, figuras oculadas o las barras verticales o zigzags, que en algunos casos tienen su paralelismo formal en el sudoeste de la Península, confirmando, una vez más los fenómenos de interacción, directa o indirecta, entre comuni- dades de la Prehistoria Reciente que ocuparon zonas alejadas por centenares de kilómetros.

Uno de los aspectos más interesantes que la presencia de Arte Esquemático en el noroeste peninsular permite analizar, es la relación entre diferentes tradiciones rupestres de la Prehistoria Reciente. Es precisamente en el noroeste de la Península Ibérica donde tiene lugar la zona de encuentro entre dos grandes tradiciones rupestres, la Atlántica y la Esquemática (Fig. 10). Existe un debate abierto sobre la cronología del Arte Atlántico, así esta tradición rupestre se habría iniciado en el Neolítico (Twohig 1981, Bradley 1997, Beckensall 2002, Alves 2009) y podría pervivir hasta la Edad del Hierro (Anati 1968, Santos, 2012, Bettencourt y Santos 2018), aunque también hay propuestas que sitúan el arte Atlántico entre el Calcolítico y parte de la Edad del Bronce, concretamente entre el 3000 y el 1500 a. C. (Rodríguez Rellán et al. 2019) e incluso con una cronología más corta dentro del III milenio a. C. (Peña Santos y Rey García 2001). En todo caso, cualquiera de estas propuestas implica una coetaneidad, al menos parcial, con el Arte Esquemático.

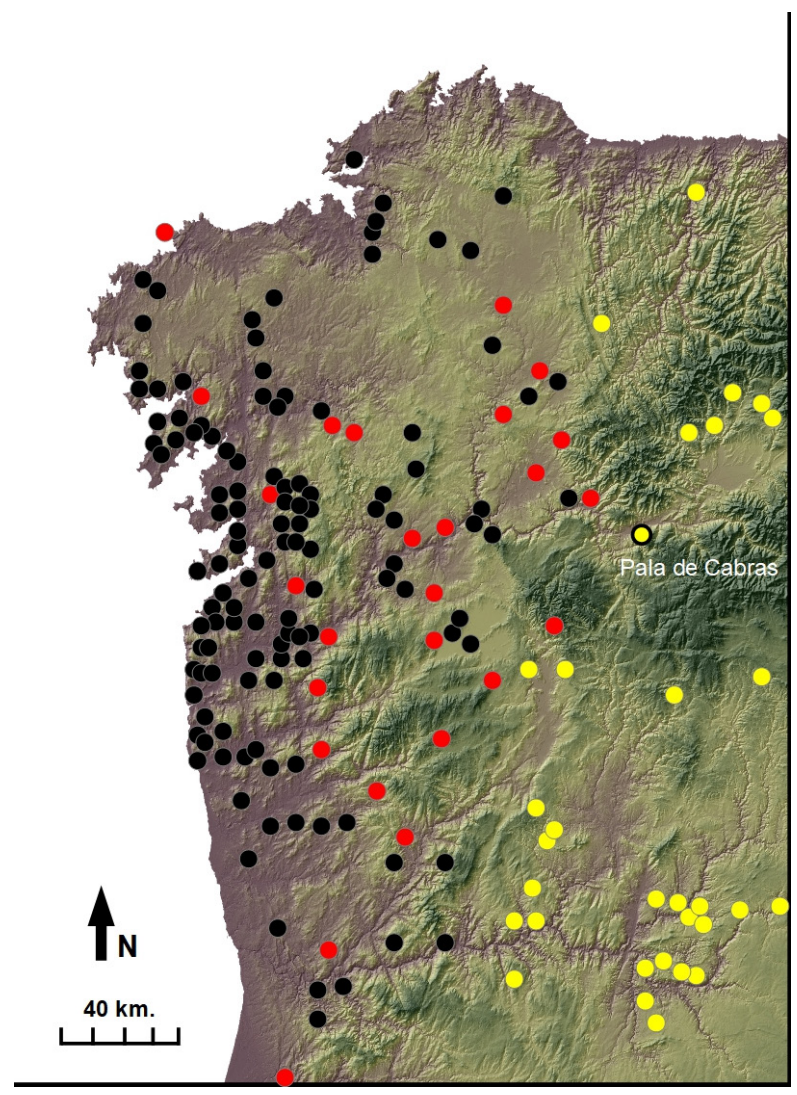

Fig. 10. Zona geográfica de encuentro entre las artes rupestres de tradición Atlántica (los puntos negros representan el Arte Atlántico clásico y los rojos el denominado Esquemático Atlántico) y Esquemática (puntos amarillos). 
Los recientes descubrimientos están ayudando a perfilar esta zona de contacto entre ambos grupos estilísticos, nos referimos a Penedo Gordo en Vilardevós, Ourense (Alves y Comendador Rey 2017), Cova dos Mouros en Baleira, Lugo (Rodríguez Rellán et al. 2019) y más recientemente las de Castelo de Lobarzán en Monterrei, también en Ourense ${ }^{8}$. Estos últimos hallazgos, junto con el de Casaio, parecen concretar un área de encuentro entre ambas tradiciones que estaría localizada en torno a una imprecisa línea que tendría como referencia los valles del Támega, del Eo y las estribaciones occidentales de las sierra orientales de Galicia. Para la zona portuguesa, la zona de contacto entre ambas tradiciones habría quedado definida con la catalogación de Pala Pinta (Santos Júnior 1933), el abrigo de Foz do Tua (Teixeira y Sanches 2017) o Regato das Bouças (Sanches et al. 2016) entre otros sitios, que prolongarían ese límite por el valle del Támega y las sierras de Marão y Alvão.

La existencia de dos grandes zonas en la Península Ibérica, una más occidental donde predominan los grabados rupestres y otra central y oriental donde predominan las pinturas, es un hecho constatado por varios arqueólogos. P. Bueno et al. (2009) han señalado la existencia de dos grandes territorios desde el punto de vista de la técnica empleada en las representaciones rupestres. Así, en la zona más occidental, existe un claro predominio de grabados, mientras que, en la mayor parte de la Península, en el mismo marco temporal, son las pinturas la manifestación predominante. De este modo, sugieren estos autores que la técnica empleada en los paneles, formarían también parte del sistema identitario de las comunidades que habitarían, lo que denominan, "Territorios Tradicionales". Así mismo, H. Collado y J. García, afirman que en el tercio occidental peninsular, el Arte Esquemático se manifiesta recurrentemente a través de la pintura y del grabado, mientras que en las zonas más orientales de la Península el arte grabado esquemático es prácticamente inexistente (Collado Giraldo y García Arranz 2013). La existencia de estas dos grandes regiones peninsulares, la que ocuparía el cuarto occidental por un lado y la que se distribuye por el resto de la península, es lo que convierte la localización geográfica de Pala de Cabras en uno sus aspectos más interesantes. Las zonas de contacto en-

Dado a conocer por la directora de la intervención Beatriz Comendador en el verano de 2019. https://www.gciencia. $\mathrm{com} /$ historias-gc/pinturas-rupestres-oimbra-monterrei/ tre diferentes tradiciones artísticas es un fenómeno muy infrecuente en el conjunto de Europa occidental, sin embargo es un hecho reiterado en varios puntos de la Península Ibérica debido a la diversidad de estilos rupestres existentes. Pala de Cabras se encuentra, por lo tanto, en una zona privilegiada para el estudio de los fenómenos de interacción entre tradiciones rupestres.

Los grabados al aire libre situados al sur de la cuenca del Duero, como por ejemplo los existentes en el Guadiana Internacional (Collado Giraldo 2006, Baptista y Santos 2013), presentan claras influencias del Arte Esquemático, observable en la presencia de antropomorfos ancoriformes o antropomorfos en Y. Esto mismo se puede afirmar de los grabados rupestres del Tajo, también con ancoriformes, pectiniformes, ramiformes y soliformes (Gomes 2010, Garcês 2018). En el caso del valle del Duero los grabados rupestres que representan inequívocamente motivos típicos del Arte Esquemático, penetran por este valle incluso hasta puntos del Alto Duero (Gómez-Barrera 1992). Sin embargo, la zona de contacto del noroeste presenta una evidente peculiaridad. Al norte del Duero las influencias entre estilos son casi inexistentes, aunque quizás podríamos mencionar como excepción Cachão da Rapa. Aquí se documentan diseños cuadrangulares que recuerdan a algunos de los grabados del Gião en Arcos de Valdevez (Baptista 1981) y Lamelas en Ribeira de Pena (Sanches y Gomes 2017), grabados que forman parte de un numeroso conjunto de petroglifos situados entre el área más clásica del Arte Atlántico al oeste y el Arte Esquemático más oriental que recibió la denominación provisional de Arte Esquemático-Atlántico (Santos Estévez 2007).

La influencia a la inversa, es decir, la presencia de motivos que inequívocamente podemos considerar como pertenecientes al Arte Esquemático en paneles Atlánticos o de tradición Atlántica son también casi inexistentes. Quizás podríamos mencionar dos excepciones, que, curiosamente, no se sitúan en las zonas más cercanas al territorio de distribución del Arte Esquemático. Nos referimos a un panel con grabados de Coutadas en As Neves (Pontevedra) donde se observan varios antropomorfos en "phi" acompañadas de otras figuras tales como antropomorfos esquemáticos "orantes". La coincidencia en

Un calco de este panel ha sido publicado en Pereira y Fábregas (2019: 25). 
un mismo panel de varios motivos típicos del Arte Esquemático podrían reforzar la idea de que pudiera tratarse de diseños importados. Un segundo caso, algo más dudoso, lo encontramos en la estación de Escorregadoira da Raposeira de Campo Lameiro (Pontevedra) con una figura semejante a algunas variantes de figuras oculadas simplificadas (Fig. 11). A día de hoy, es dificil encontar más ejemplos en los que podamos constatar influencias del
Arte Esquemático. Nos inclinamos por no incluir soliformes, antropomorfos y zoomorfos esquemáticos, ya que la representación simplificada de ciertos motivos reduciéndolos a sus líneas más básicas, lleva a soluciones muy semejantes sin necesidad de influencias, como así lo atestigua la presencia de este tipo de diseños en numerosas artes rupestres de cronología diversa y repartidos por varios continentes.
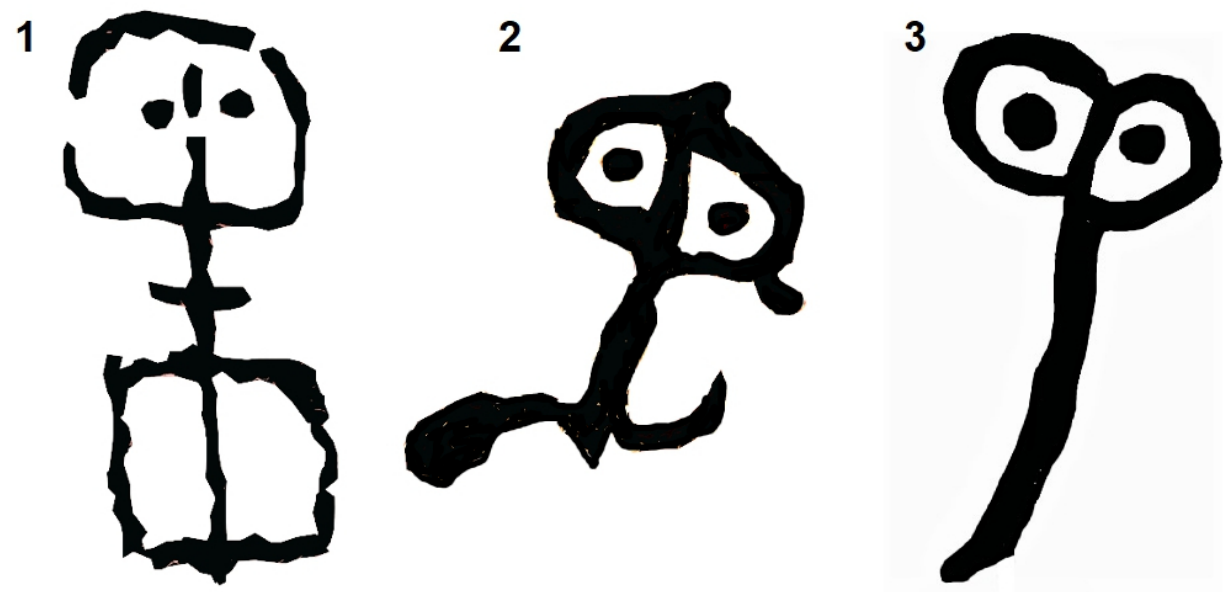

Fig. 11. Figuras oculadas en grabados rupestres gallegos:

1. Escorregadoira da Raposeira (Campo Lameiro); 2 y 3 Coutadas (As Neves).

El Arte Rupestre Atlántico, posee una distribución general evidentemente costera. Aunque es posible encontrar petroglifos pertenecientes a este estilo a $100 \mathrm{~km}$. de la costa, lo cierto es que, a partir de los $30 \mathrm{~km}$. de distancia respecto al mar, el número de yacimientos disminuye drásticamente. De hecho, el área nuclear del Arte Atlántico de la Península Ibérica, esto es, la zona de mayor densidad de petroglifos, abarca una región de $130 \mathrm{~km}$. de norte a sur por 50 $\mathrm{km}$. de oeste a este, configurando de este modo, un territorio tendido a lo largo de la costa comprendida entre el cabo Fisterra y el río Limia, precisamente por este motivo, desde los inicios del siglo XX la tradición investigadora ha considerado como un único territorio rupestre el gallego y el del noroeste portugués. Esta tendencia costera del Arte Atlántico sería lo que explicase las afinidades con el arte rupestre de las Islas Británicas y que presente más semejanzas con grabados del Tajo portugués que con zonas más interiores de la Península Ibérica.

No obstante, llama la atención la, al menos aparente, falta de interacción entre el Arte Esquemático y Atlántico, y esto, a pesar de que, en la zona oriental de Galicia, los sitios con Arte Esquemático se localizan muy próximos a petroglifos con las características combinaciones circulares del Arte Atlántico, son, por ejemplo: Pala de Cabras, que se encuentra a 22 km. del petroglifo de Pena da Auga (Barco de Valdeorras); Cova dos Mouros en Baleira está solamente a $19 \mathrm{~km}$. del petroglifo de Monte Carballedo (Láncara) y Castelo de Lorbazán se sitúa tan solo a $13 \mathrm{~km}$. de Chaira 1 (Cualedro). Esta circunstancia, por el momento, no parece fácil de explicar, habida cuenta de la proximidad entre ambas tradiciones y de su casi segura coetaneidad. Trabajo para un futuro.

\section{Agradecimientos}

A la FCT por la financiación del proyecto Paisagem e representação do poder na Pré-história Recente: Arte Atlântica e Estátuas-Menir (SFRH/BPD/93700/2013), así como al Lab2.pt de la Universidade do Minho, a Raquel López por la revisión del texto y a Diego Torres Iglesias por el plano de visibilidades de Pala de Cabras. 


\section{Bibliografía}

Acosta Martínez, P. 1968: La pintura rupestre de España. Ed. Universidad de Salamanca. Salamanca

Acosta Martínez, P. 1984: "El arte rupestre esquemático ibérico: problemas de cronología preliminares". En F.J. Fortea Pére y F. Jordá Cerdá: F. Jordá. Oblata. Scripta Praeshistórica. Ed. Universidad de Salamanca. Salamanca: 31-61.

Alves, L.B. 2009: "O sentido dos signos - reflexões e perspectivas para o estudo da arte rupestre do pósglaciar no Norte de Portugal”. En R. De Balbín Behrmann: Arte Prehistórico al Aire Libre en el Sur de Europa. Junta de Castilla y Leon. Valladolid: 381-413.

Alves, L. y Comendador Rey, B. 2017: “Arte esquemático pintado en el noroeste peninsular: una visión integrada transfronteriza". Gallaecia 36: 11-52.

Anati, E. 1968: Arte Rupestre nelle regioni occidentali della Penisola Iberica. Centro Camuno de Studi Preistorici. Brescia.

Baptista, A. M. 1981: “A arte do Gião”. Arqueologia 3. Grupo de Estudos Arqueologicos: 56-66.

Baptista, A. M. y Santos, A. T. 2013: "A Arte Rupestre do Guadiana Português na Área de Influencia do Alqueva". Memorias d'Odiana $2^{\text {a }}$ Série. EDIA.

Barroso Ruíz, C. 1983: "Tipología de ídolos oculados en la pintura rupestre esquemática de Andalucía". Zéphyrus 36: 131-136.

Beckensall, S. 2002: "British Prehistoric Rock-Art in the Landscape". En G. Nash y C. Chippindale: European Landscapes of Rock-Art. London. Routledge: 39-70.

Bettencourt, A. M. S y Santos-Estévez, M. 2018: A geografia mágica do monte Sāo Silvestre atraves da arte rupestre. Ed. Lab2, pt. Universidade do Minho.

Becares Pérez, J. 1990: “Uniformidad conceptual en los ídolos del Calcolítico peninsular”. Zéphyrus 43: 87-94.

Bradley, R. 1997: Rock Art and the Prehistory of Atlantic Europe. London. Routledge.

Breuil, H. 1935: Les peintures rupestres schématiques de la péninsule Ibérique. Vol. IV. Fondation SingerPolignac.

Bueno Ramírez, P., Balbín Behrmann, R. 1996: "El papel del elemento antropomorfo en el arte megalítico". Révue Archéologique de l'Ouest 8: 41-64.

Bueno Ramírez, P., Balbín Behrmann, R, y Barroso Bermejo, R. 2009: "Constructores de Megalitos y Marcadores Gráficos. Diacronías y Sincronías en el Atlántico Ibérico”. En R. De Balbín, P. Bueno, R. González y C. Del Arco: Grabados Rupestres de la fachada Atlántica Europea y Africana. BAR International Series 2043. Archaeopress. Oxford: 149-172

Carrasco, J. y Pastor, M. 1983: “Aproximación al fenómenos rupestre esquemático en la cuenca alta del Guadalquivir". Zephyrus 36: 167-180.

Carrera Ramírez F. y Fábregas Valcarce, R. 2002: “Datación radiocarbónica de pinturas megalíticas del noroeste peninsular". Trabajos de Prehistoria 59: 157-166.

Collado Giraldo, H. 1997: La pintura rupestre esquemática en el término de Alburquerque (Badajoz). Martínez de Balastegui. Mérida.

Collado Giraldo, H. 2006: Arte rupestre del valle del Guadiana. El conjunto de grabados del Molino Manzánez (Alconchel-Cheles, Badajoz). Memorias d'Odiana 4 ${ }^{\text {a }}$ Série. EDIA.

Collado Giraldo, H. y García Arranz, J. J. 2013: "Reflexiones sobre la fase inicial del arte rupestre esquemático en Extremadura a raíz de las recientes investigaciones”. En J. Martínez y M. Hernández: Arte Rupestre Esquemático en la Península Ibérica. Actas del II Congreso. Ayuntamiento de Vélez Blanco. Vélez Blanco: 287-299.

Contador de Argote, J. 1747: Memórias para a História Ecclesiástica do Arcebispado de Braga (Tomo I). Lisboa.

De Blas Cortina, B. y Carrocera Fernández, E. 1985: "La cova del Demo (Boal): una estación de arte rupestre esquemático en el occidente asturiano". Boletín del Seminario de Estudios de Arte y Arqueología: BSAA 51: 47-82.

Fernández Rivera, B. 1987: “Aproximación al estudio de las pinturas rupestres esquemáticas del Abrigo de El Castillón, Santa Eulalia de Tabara (Zamora)". Stvdia Zamorensía. Histórica 8: 29-37.

García Guinea, M. A. 1963: "Le nouveau et important foyer de peintures levantines à Nerpio (Albacete, Espagne)". Bulletin de la Société Préhistorique de l'Ariège 18: 17-55.

García Atienzar, G. 2006: “Ojos que nos miran. Los ídolos oculados entre las cuencas del Júcar y Segura”. En J. Martínez y M. Hernández: Actas del I Congreso de Arte Rupeste Esquemático en la Península Ibérica (Comarca de Los Vélez, 2004). Ayuntamiento de Vélez Blanco. Vélez Blanco: 223-234. 
Garcês, S. 2018: Corpus do Complexo de Arte Rupestre do Vale do Tejo. Suplemento especial da série Area Domeniu. Instituto Terra é Memoria.

Gomes, M. V. 2010: Arte Rupestre do Vale do Tejo. Um Ciclo Artístico-Cultural Pré e Proto-Histórico. Universidade de Lisboa. Lisboa.

Gómez-Barrera, J. A. 1992: Grabados rupestres postpaleolíticos del Alto Duero. Museo Numantino. Soria.

Gómez-Barrera, J.A. 2001: Pinturas rupestres de Valonsadero y su entorno. Caja Rural de Soria. Soria

Grande del Brío, R. 1982: "Descubrimiento de pinturas rupestres en la Sierra de la Culebra". Zephyrus 3435: $145-158$.

Gutiérrez González, J. M., Avello Álvarez, J. L. 1986: Las pinturas rupestres esquemáticas de Sésamo, Vega de Espinareda (León). Centro de Investigación y Museo de Altamira. Monografías, 12.

Hernández Pérez, M. S. 2006: "Artes esquemáticos en la Península Ibérica: el paradigma de la pintura esquemática”. En J. Martínez y M. Hernández: Arte Rupestre Esquemático en la Península Ibérica. Actas del I Congreso. Ayuntamiento de Vélez Blanco. Vélez Blanco: 13-32.

Hurtado, V. 2008: "Ídolos, estilos y territorios de los primeros campesinos en el sur peninsular". Acercándonos al pasado: prehistoria en 4 actos. Ministerio de Cultura. Madrid.

Maicas Ramos, R. 2010: "Los ojos que todo lo ven: oculados en el sureste". Ojos que nunca se cierran. Ídolos en las primeras sociedades campesinas. Ministerio de Cultura. Madrid: 115-136.

Martínez García, J. 2002: "Pintura rupestre esquemática: el panel, espacio social". Trabajos de Prehistoria 59.1: 65-87.

Mesquita, H. 1922: “Arte rupestre em Portugal. A Pala Pinta”. In Terra Portuguesa. Lisboa 4: 145147.

Morán, C. 1933: "Nuevas pinturas rupestres”. Actas y memorias de la Sociedad española de Antropología, Etnografia y Prehistoria, XII: 137-148.

Pereira Martínez, X. y Fábregas Valcarce, F. 2019: "Novos datos sobre a arte rupestre do Miño Litoral o concello de As Neves (Pontevedra)". Gallaecia 38: 9-32.

Rodríguez Rellán, C., Fábregas Valcarce, R. y Carrera Ramírez, F. 2019: "Intervención arqueológica en el abrigo de Cova dos Mouros. Un primer ejemplo de pintura esquemática en Galicia". Munibe 70: 185205.

Peña Santos, A. de la y Rey García, J. M. 2001: Petroglifos de Galicia. Ed. Vía Láctea. Oleiros.

Sanches, M. J. 1997: Pré-história Recente de Trás-os-Montes e Alto Douro. Sociedade Portuguesa de Antropologia e Etnologia. Porto.

Sanches, M. J., Morais, P. y Teixeira, J. 2016: "Escarpas rochosas e pinturas na Serra de Passos/Sta Comba (Nordeste de Portugal)". En M.J. Sanches y D. Cruz: Actas da II Mesa Redonda "Artes Rupestres da Pré-história e da Proto-história". Estudo, Conservação e Musealização de Maciços Rochosos e Monumentos Funerários (Porto, Facultade de Letras, 10, 11 e 12 de Novembro de 2011). Centro de Estudos Pré-histo'ricos: 71-117.

Sanches, M. J. y Gomes, N. C. 2017: "The Lamelas rock art site as a fundamental contributor to the knowledge of post-glacier art in the north-western Iberia". En A.M.S. Bettencourt, M. Santos-Estevez, H.A. Sampaio, D. Cardoso: Recorded Places, Experienced Places. The Holocene Rock Art of the Iberian Atlantic Northwest. British Archaeological Reports, Archaeopress. Oxford: 39-47.

Sanchidrián Torti, J. L. Y Muñoz Vivas, V. E. 1990: "Cuestiones sobre las manifestaciones parietales postpaleolíticas en la cueva de La Pileta (Benaoján, Málaga)". Zephyrus 43: 151-163.

Santos Junior, J. R. 1933: "O abrigo pre-historico de "Pala Pinta", Trabalhos da Sociedade Portuguesa de Antropologia e Etnologia VI: 141-148.

Santos-Estévez, M. 2007: "Petroglifos y paisaje social en la prehistoria reciente del NW de la Península Ibérica". Traballos de Arqueoloxía e Patrimonio TAPA 38. IEGPS-CSIC. Santiago de Compostela.

Santos-Estévez, M. 2012: "Atlantic Rock Art: Transformation and Tradition during Late Prehistory". En C. Berrocal, L. García Sanjuán y A. Gilman Guillén: The Prehistory of Iberia. Debating Early Social Stratification and the State, ed. Cruz Berrocal, García Sanjuán and Gilman Guillén. New York: Routledge: 231-248.

Silva, E. J. L. 1993: "Représentations humaines sur deux monuments mégalithiques de la région nord du Portugal". In Les représentations humaines du Néolithique à l'Âge du Fer. 115 Congrès National des Sociétés Savantes, Pré et Protohistoire (Avignon 1990): 21-27. Paris.

Soria, M., López, M. y Zorrilla, D. 2013: El arte rupestre en las sierras giennenses. Patrimonio de la Humanidad. Las sierras orientales y meridionales. Instituto de Estudios Giennenses. Jaén.

Teixeira, J. C. y Sanches, M. J. 2017. O abrigo da Foz do Rio Tua no contexto da arte Peleolítica e PósPaleolítica do noroeste da península Ibérica. Portugalia 38: 9-48. 
Tejerizo García, C. y Rodríguez Gutiérrez, A. 2019: “Arqueología e la guerra después de la guerra: la organización de la resistencia antifranquista en el noroeste de la Península Ibérica". Vestígios. Revista Latino-Americana de Arqueología Histórica 13 (2): 9-35.

Tejerizo García, C., Alonso Toucido, F., Martínez Panizo, L., Rodríguez-González, C., Fernández-Pereiro, M. y Rodríguez-Gutiérrez, A, 2020: "Hallazgo de un conjunto de pintura esquemática prehistórica en el sitio de "Pala de Cabras" en Casaio". Revista PH Instituto Andaluz del Patrimonio Histórico, 100: 44-63.

Twohig, E. S. 1981: The Megalithic Art of Western Europe. Oxford. Clarendon Press.

Utrilla, P. y Baldellou, V. 2002. Cantos pintados neolíticos de la Cueva de Chaves (Bastarás, Huesca). Salduie 2: 45-126.

Vázquez Varela, J. M. 1996. Prehistoria. Las religiones a través del arte y del grafismo. En Las Religiones en la Historia de Galicia. (Coord: M. V. García Quintela): 15-32. 